Check for updates

Cite this: RSC Adv., 2018, 8, 28676

Received 24th April 2018

Accepted 4th August 2018

DOI: $10.1039 / c 8 r a 03519 a$

rsc.li/rsc-advances

\section{Ammonium bio-ionic liquids based on camelina oil as potential novel agrochemicals $\uparrow$}

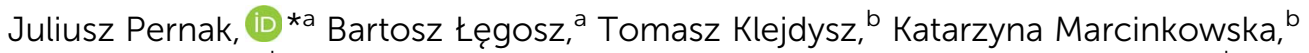 \\ Jacek Rogowski, ${ }^{\text {b }}$ Danuta Kurasiak-Popowska ${ }^{c}$ and Kinga Stuper-Szablewska ${ }^{d}$
}

Third generation bio-ionic liquids (bio-ILs) were synthesized based on cheap and increasingly available camelina oil. The ionic liquids were obtained with high yield based on the reaction between camelina oil, which contained the following carboxylic acids: C18:3 $\omega-3$ linolenic $>30 \%$, C20:1 eicosenoic 28\%, C18:2 $\omega-6$ linoleic 13\%, C18:1 oleic $13 \%$, C16:0 palmitic $4.5 \%$, C22:1 erucic $4.5 \%$ and C18:0 stearic $2.5 \%$, and quaternary ammonium hydroxides comprising cations such as: choline, di(hydrogenated tallow)dimethylammonium, oleylmethylbis(2hydroxyethyl)ammonium, benzalkonium, tetradecyltrimethylammonium, tetramethylammonium and didecyldimethylammonium. The synthesized bio-ILs were characterized as high viscosity liquids which are thermally stable and their solubility in water and organic solvents depended on the type of cation. Two extreme examples of bio-ILs include the water soluble one comprising choline as the cation and the one comprising the di(hydrogenated tallow)dimethylammonium cation, which is soluble in hexane. The presented results show the importance of ammonium bio-ILs as antifeedants with a wide spectrum of activity. The tested beetles (Insecta: Coleoptera) of storage pests: grain weevil (Sitophilus granarius (L.)), confused flour beetle (Tribolium confusum Duv.) and khapra beetle (Trogoderma granarium Ev.) presented notable differences in terms of susceptibility to the synthesized ILs. The synthesized bio-ILs are effective adjuvants for herbicides belonging to the sylfonylurea group. They exhibited high activity despite the fact they were applied at a dose almost half that used for commercial adjuvants, which opens the era of adjuvant ILs. Aside from its use in the production of biodiesel, renewable diesel and renewable jet fuel, camelina oil is starting to become a potential resource for the production of novel agrochemicals.

\section{Introduction}

Ionic liquids (ILs) are a well-known group of chemical compounds, and have gained high popularity due to their unique properties. The number of possible cation-anion combinations is estimated to be over $10^{18}$, making them significant for numerous applications. ${ }^{1}$ Taking into account the physicochemical and biological properties of ILs, a general yet practical classification of these compounds into three generations was proposed in 2007. ${ }^{2}$ The first generation comprises ILs with specific physical properties, obtained by careful selection of appropriate cations and anions, whereas the second generation additionally considers their chemical properties. The

${ }^{a}$ Poznan Univeristy of Technology, Faculty of Chemical Technology, Berdychowo 4, 60-965 Poznań, Poland. E-mail: juliusz.pernak@put.poznan.pl

${ }^{b}$ Institute of Plant Protection - National Research Institute, Wegorka 20, 60-101 Poznań, Poland

'Poznan University of Life Sciences, Faculty of Agronomy and Bioengineering, Dojazd 11, 60-632 Poznań, Poland

${ }^{d}$ Poznan University of Life Sciences, Faculty of Wood Technology, Wojska Polskiego 75, 60-625 Poznań, Poland

$\dagger$ Electronic supplementary information (ESI) available. See DOI: $10.1039 / \mathrm{c} 8 \mathrm{ra03519a}$ third generation includes ILs, which simultaneously exhibit targeted biological properties as well as desired physical and chemical properties. An example of the most recent generation may be the conversion of popular drugs into ILs in order to increase their medical potential. ${ }^{3-5}$ However, this effect is not only limited to pharmaceuticals. In 2011 (ref. 6) a novel group of ILs called herbicidal ionic liquids (HILs) which comprise a herbicidal anion was introduced. Currently there are literature reports regarding HILs based on the following herbicides: 2,4$\mathrm{D},{ }^{7} \mathrm{MCPA},{ }^{6} \mathrm{MCPB},{ }^{8} \mathrm{MCPP},{ }^{9}$ dichlorprop,${ }^{10}$ dicamba, ${ }^{11,12}$ clopyralid, ${ }^{13}$ fomesafen, ${ }^{14}$ bentazon, ${ }^{15}$ glyphosate, ${ }^{16,17}$ metsulfuron methyl ${ }^{18}$ nonanoic acid ${ }^{19}$ and picloram. ${ }^{20}$ The combination of two different types of biological activity is also known to date, as exemplified by dual function ILs which function as both herbicides and growth regulators. ${ }^{21}$ Similar to drugs, the transformation of popular fungicides into the IL structure was also carried out. ${ }^{22,23}$ Additionally, some ILs were described as feeding deterrents, protecting stored crops from pests. ${ }^{24}$ Recently there have been examples of studies regarding the chemical modification of plant resistance inducer, benzo[1,2,3] thiadiazole-7-carboxylate (BTH). ${ }^{25,26}$ When natural resources are used for the synthesis of third generation ILs, they may be classified as bio-ILs. ${ }^{17,27-29}$ Agriculture needs a new chemical 
platform, for example third generation ILs, to help with crucial issues, such as resistance to herbicides.

Triglycerides present in vegetable oils are an attractive source of chemicals, mainly fatty acids, which may be a source of anions for the synthesis of ILs. Camelina is an annual oil plant, which belongs to the Brassicaceae family. Its attractiveness is associated with its resistance to negative soil and climate conditions as well as high tolerance to diseases such as Alternaria brassicae and pests. This allows to use low-class soils for its cultivation, which are not suitable for other crops. Additionally, camelina possesses unique agronomic traits, which include a short vegetation time and higher tendency to now sow seeds compared to flax..$^{30}$ Consequently, the attractive production economics and minimal input requirements regarding its cultivation provide further added advantages.

During recent years there has been a growing interest in camelina due to the unique composition of camelina oil. The adaptation of camelina to the vast areas of the world, high oil content $(28-40 \%)$ combined with its unique oil composition and properties make it a suitable oil source for the production of biofuels, jet fuel, bio-based products, feed, and food. Camelina oil is rich in oleic $(18: 1,14-18 \%)$, linoleic, $(18: 2 \omega-6,15-$ $23 \%)$, linolenic $(18: 3 \omega-3,28-40 \%)$, and eicosenoic $(20: 1,12-$ $17 \%)$ acid. ${ }^{31}$ Currently most attention is directed to the use of camelina oil for the production of biodiesel, renewable diesel and renewable jet fuel. ${ }^{32}$

The aim of this study was to use camelina oil as a resource for the synthesis of bio-ILs and evaluate the potential application of the obtained compounds in agricultural practices. This study was focused on the synthesis of novel bio-ILs and evaluation of their physicochemical properties, deterrent and adjuvant activity.

\section{Results and discussion}

Camelina oil used in this study was analysed in terms of its fatty acid profile using HPLC. The presence and content of following main acids were established: C18:3 $\omega-3 \alpha$-linolenic (ALA) $>30 \%$, C20:1 eicosenoic 28.22\%, C18:2 $\omega-6$ linoleic (LA) and C18:1 oleic at $12.84 \%$ and $13.35 \%$, respectively. The content of C16:0 palmitic (PA) and C22:1 erucic (EU) was below 5\% (4.45\% and $4.57 \%$, respectively), C18:0 stearic acid was at $2.47 \%$, C20:2 eicosadienoic at $1.86 \%$, while C24:1 nervonic, C20:0 arachidic (ARA), C21:0 heneicosanoic and C24:0 lignoceric were present at $<1 \%(0.98 \%, 0.86 \%, 0.61 \%$ and $0.19 \%$, respectively). The presence of C14:0 myristic acid, C15:0 pentadecanoic acid, C15:1 pentadecenoic acid, C16:1 palmitoleic acid, C17:0 margaric acid, C17:1 10-heptadecenoic acid and C18:3 $\omega-6 \gamma$-linolenic acid (GLA) was not detected. The acidic value of the oil was equal to $3.12 \mathrm{mg} \mathrm{NaOH} / 1 \mathrm{~g}$, anisidine value was equal to 0.39 , peroxide number was equal to 0.88 , total oxidation value TOTOX was equal to 2.31 , smoke point (which refers to the temperature at which the oil sample begins to smoke) was equal to $159^{\circ} \mathrm{C}$.

Ionic liquids with camelina oil anions were synthesized according to the previously described procedure. ${ }^{28}$ The progress and conditions of the reactions were monitored using a MettlerToledo EasyMax 102 system. Quaternary ammonium cations: (tetramethylammonium, tetradecyltrimethylammonium, didecyldimethylammonium, benzalkonium, choline, di(hydrogenated tallow)dimethylammonium and oleylmethylbis(2hydroxyethyl)ammonium) with different structures were used during the syntheses in order to investigate their influence on biological properties. The cation structures did not affect the reaction time. The $\mathrm{pH}$ of the solutions stabilized after 20 minutes. The reaction were carried out in propan-2-ol and glycerine was the by-product (Scheme 1). All the synthesized products were obtained as high viscosity liquids at ambient temperature and did not exhibit a tendency to undergo crystallisation, which allows to classify them as ILs. In this case the anion consists of a mixture of fatty acids. The synthesized mixtures of bio-ILs (anion: C18:3 $\omega-3$ linolenic $>30 \%$, C20:1 eicosenoic 28\%, C18:2 $\omega$-6 linoleic 13\%, C18:1 oleic 13\%, C16:0 palmitic $4.5 \%$, C22:1 erucic $4.5 \%$ and C18:0 stearic $2.5 \%$ ) will posses different physicochemical properties compared to pure ILs. This has been confirmed by recently published studies regarding binary mixtures of protic ILs derived from fatty acids, which presented a marked nonideal melting profile with the formation of solid solution. ${ }^{33}$

Seven bio-ILs were obtained with high yields, as presented in Table 1. This group includes novel bio-ILs which comprise e.g. the cholinium cation $\mathbf{5}$ as well as ammonium cations with oleyl 6 or tallow 4 substituents.

The structures of ILs were confirmed by analysis of NMR spectra. The signals from the anion were identified in the range from $0.87 \mathrm{ppm}$ to $0.90 \mathrm{ppm}$ for protons of methyl groups, while protons in the methylene group bonded with the methyl group occurred as signals from $0.96 \mathrm{ppm}$ to $0.99 \mathrm{ppm}$. The signals for methylene groups in the alkyl chain occurred in range from $1.22 \mathrm{ppm}$ to $1.38 \mathrm{ppm}$. Methylene protons in position $\beta$ to the carboxylic group were noted as peaks from $1.54 \mathrm{ppm}$ to $1.77 \mathrm{ppm}$. Protons bonded to carboxylic carbon atom were<smiles>[R]C(=O)OCC(COC([R])=O)OC([R])=O</smiles>

Scheme 1 The synthesis methods of preparation of ammonium ILs with fatty acid anions isolated from camelina oil. 
Table 1 Characterization of synthesized ammonium bio-ILS

\begin{tabular}{|c|c|c|c|c|}
\hline IL & $\mathrm{R}^{1}$ & $\mathrm{R}^{2}$ & $\mathrm{R}^{3}$ & Yield [\%] \\
\hline 1 & $\mathrm{CH}_{3}$ & $\mathrm{CH}_{3}$ & $\mathrm{CH}_{3}$ & 93 \\
\hline 2 & $\mathrm{CH}_{3}$ & $\mathrm{CH}_{3}$ & $\mathrm{C}_{14} \mathrm{H}_{29}$ & 91 \\
\hline 3 & $\mathrm{CH}_{3}$ & $\mathrm{C}_{10} \mathrm{H}_{21}$ & $\mathrm{C}_{10} \mathrm{H}_{21}$ & 93 \\
\hline 4 & $\mathrm{CH}_{3}$ & Hyd. tallow $^{a}$ & Hyd. tallow ${ }^{a}$ & 88 \\
\hline 5 & $\mathrm{CH}_{3}$ & $\mathrm{CH}_{3}$ & $\mathrm{C}_{2} \mathrm{H}_{4} \mathrm{OH}$ & 92 \\
\hline 6 & $\mathrm{C}_{2} \mathrm{H}_{4} \mathrm{OH}$ & $\mathrm{C}_{2} \mathrm{H}_{4} \mathrm{OH}$ & Oleyl $^{b}$ & 86 \\
\hline 7 & $\mathrm{CH}_{3}$ & $\mathrm{CH}_{2} \mathrm{Ph}$ & Alkyl $^{c}$ & 90 \\
\hline
\end{tabular}

${ }^{a}$ Hydrogenated tallow-mixture of saturated $(97 \%)$ or unsaturated $(3 \%)$ alkyl substituents- $\mathrm{C}_{12}-1 \%, \mathrm{C}_{14}-4 \%, \mathrm{C}_{16}-31 \%, \mathrm{C}_{18}-64 \%$ in Arquad 2HT. ${ }^{b}$ Oleyl-mixture of saturated $(18 \%)$ or unsaturated $(82 \%)$ alkyl substituents- $\mathrm{C}_{12}-5 \%, \mathrm{C}_{14}-1 \%, \mathrm{C}_{16}-14 \%, \mathrm{C}_{18}-80 \%$, in Ethoquad O-12. ${ }^{c}$ Alkyl- $\mathrm{C}_{12}-40 \%, \mathrm{C}_{14}-60 \%$.

identified as signals between 2.75 and $2.82 \mathrm{ppm}$. Protons in position $\alpha$ to multiple bonds in alkyl chains occurred in range from 1.96 and $2.15 \mathrm{ppm}$. Protons in double bonds were noted between 5.29 and $5.41 \mathrm{ppm}$.

Protons from aliphatic substituents in the cation generated signals in ranges from $0.87 \mathrm{ppm}$ to $0.90 \mathrm{ppm}$. Methylene groups in positions $\gamma, \beta$ and $\alpha$ to the quaternary nitrogen atom generated signals in ranges $1.53-1.69 \mathrm{ppm}, 1.96-2.15 \mathrm{ppm}$ and 3.22$3.45 \mathrm{ppm}$, respectively. Methyl groups bonded directly to the charged nitrogen atom were identified as signals between $3.19 \mathrm{ppm}$ and $3.38 \mathrm{ppm}$. Protons in 2-hydroxyethyl groups occurred as signals in ranges 3.56-3.71 ppm and 4.04-4.05 ppm for protons in groups in positions $\alpha$ and $\beta$ to the quaternary nitrogen atom. Methylene group between the nitrogen atom and the aromatic ring generated a signal at $4.72 \mathrm{ppm}$. Protons in aromatic ring were identified as signals between $7.42 \mathrm{ppm}$ and $7.56 \mathrm{ppm}$.

The obtained ILs were investigated for phase transitions and thermal stability. The results were presented in Table 2.

The studied ILs exhibited glass transition temperatures in the range from $-69.3{ }^{\circ} \mathrm{C}(7)$ to $-25.1{ }^{\circ} \mathrm{C}(2)$. No glass transition was observed for di(hydrogenated tallow)dimethylammonium (4). ILs presented multiple crystallization and melting steps, which can be explained by polymorphism of natural oils. This was also noted in case of ILs derived from canola and coconut oils. ${ }^{27}$ Single transitions were noted for ILs with tetradecyltrimethylammonium (2) and didecyldimethylammonium (3)

Table 2 Thermal characteristics of the synthesized bio-ILs

\begin{tabular}{llllll}
\hline IL & $T_{\mathrm{g}},{ }^{a}\left[{ }^{\circ} \mathrm{C}\right]$ & $T_{\mathrm{c}},{ }^{b}\left[{ }^{\circ} \mathrm{C}\right]$ & $T_{\mathrm{m}},{ }^{c}\left[{ }^{\circ} \mathrm{C}\right]$ & $T_{\text {onset5 }},{ }^{d}\left[{ }^{\circ} \mathrm{C}\right]$ & $T_{\text {onset50 }},{ }^{e}\left[{ }^{\circ} \mathrm{C}\right]$ \\
\hline $\mathbf{1}$ & -28.2 & -14.3 & $-20.4 ; 5.6$ & 185 & 222 \\
$\mathbf{2}$ & -25.1 & -16.3 & 3.2 & 183 & 220 \\
$\mathbf{3}$ & -47.5 & -8.2 & -2.0 & 180 & 224 \\
$\mathbf{4}$ & - & $30.2 ; 47.9$ & $6.4 ; 20.3$ & 189 & 292 \\
$\mathbf{5}$ & -45.2 & -26.9 & -27.1 & 179 & 220 \\
$\mathbf{6}$ & -68.7 & $-16.7 ;-37.7$ & $5.5 ;-17.5$ & 182 & 247 \\
7 & -69.3 & $-19.4 ;-6.1$ & $-37.5 ;-9.7$ & 161 & 224
\end{tabular}

${ }^{a}$ Glass temperature. ${ }^{b}$ Crystallization temperature. ${ }^{c}$ Melting temperature. ${ }^{d}$ Decomposition of $5 \%$ of the sample. ${ }^{e}$ Decomposition of $50 \%$ of the sample. cations. The crystallization temperatures varied from $-37.7^{\circ} \mathrm{C}$ to $47.9^{\circ} \mathrm{C}$, while melting was observed between $-37.5^{\circ} \mathrm{C}$ and $20.3^{\circ} \mathrm{C}$. The obtained bio-ILs were thermally stable. The lowest temperature of decomposition of $5 \%$ of the sample was observed for benzalkonium IL (7), while in case of the remaining ILs the decomposition temperature ranged from $179{ }^{\circ} \mathrm{C}$ to $189^{\circ} \mathrm{C}$.

The solubility of the prepared bio-ILs was determined according to Vogel's Textbook of Practical Organic Chemistry. ${ }^{34}$ Representative solvents were chosen and ranked by their Snyder polarity index value in a descending order (water - 9.0, methanol - 6.6, DMSO - 6.5, acetonitrile - 6.2, acetone - 5.1, ethyl acetate -4.4 , chloroform -4.1 , toluene -2.3 , hexane -0.0 ). Tests were conducted at $20{ }^{\circ} \mathrm{C}$ under ambient pressure. The results were presented in Table 3.

All the synthesized bio-ILs were soluble in methanol, DMSO and chloroform. The difference in solubility in water as well as in hexane was strongly influenced by the structures of alkyl substituents. ILs with small-sized cations $(\mathbf{1}, \mathbf{5})$ were soluble in water after the addition of $1 \mathrm{~mL}$. The presence of long alkyl chains in the cation rapidly decreased the ability of water to dissolve the tested ILs. On the other hand, ILs with two longchained saturated substituents $(3,4)$ caused moderate solubility in hexane. The hydroxyl (6) or aromatic (7) groups did not significantly affect the solubility of ILs in the used solvents. Similar observations were made in case of ILs with anion originating from canola and coconut oils. ${ }^{28}$ The obtained bio-ILs were unaffected by the contact with water and the organic solvents. During their storage in the form of aqueous, methanol or chloroform solutions no changes in their concentrations were noted.

The obtained bio-ILs were tested in terms of their antifeedant properties towards beetles of $S$. granarius, $T$. confusum, and larvae of $T$. confusum and T. granarium. The insects were grown on a wheat grain or whole-wheat meal diet in laboratory colonies, which were maintained at $26 \pm 1{ }^{\circ} \mathrm{C}$ and $60 \pm 5 \%$ relative humidity. Choice and no-choice tests for insect-feeding were conducted following a described procedure. ${ }^{35}$ Their activity was compared with the results obtained for azadirachtine - one of the most efficient feeding deterrent occurring in nature. Values of coefficients, $A$ (absolute coefficient of

Table 3 Solubility of synthesized bio-ILs ${ }^{a}$

\begin{tabular}{|c|c|c|c|c|c|c|c|c|c|}
\hline \multirow[b]{2}{*}{ IL } & \multicolumn{9}{|c|}{ Solvent } \\
\hline & A & B & $\mathrm{C}$ & $\mathrm{D}$ & $\mathrm{E}$ & $\mathrm{F}$ & $\mathrm{G}$ & $\mathrm{H}$ & I \\
\hline 1 & + & + & + & - & - & - & + & & - \\
\hline 2 & - & + & + & - & - & - & + & - & - \\
\hline 3 & - & + & + & - & - & - & + & - & $+1-$ \\
\hline 4 & - & + & + & - & - & - & + & - & $+1-$ \\
\hline 5 & + & + & + & - & - & - & + & - & - \\
\hline 6 & - & + & + & - & - & - & + & - & - \\
\hline 7 & - & + & + & - & - & - & + & - & - \\
\hline
\end{tabular}

${ }^{a}$ A-water, B-methanol, C-DMSO, D-acetonitrile, E-acetone, F-ethyl acetate, G-chloroform, H-toluene, I-hexane; solubility: “+” - good, "+/_" - moderate, "-" - not visible/none. 
deterrence) and $R$ (relative coefficient of deterrence) were calculated as follows:

$$
\begin{gathered}
A=\frac{\mathrm{CC}-\mathrm{TT}}{\mathrm{CC}+\mathrm{TT}} \times 100 \\
R=\frac{C-T}{C+T} \times 100
\end{gathered}
$$

where CC is the average weight of the food consumed in the control, TT means the average weight of the food consumed in the no-choice test, while $C$ and $T$ express the average weights of the food consumed in the choice test. The sum of these two coefficients $(T)$ explains deterrent activity: 200-151 very good, 150-101 good, 100-50 medium, <50 weak.

The results calculated for beetles of $S$. granarius were presented in Fig. 1. The blue line represents the value noted for azadirachtine.

The presented results show moderate antifeedant properties of the synthesized bio-ILs. The highest result was reached in case of didecyldimethylammonium IL (3), which was classified as a very good deterrent (deterrent activity $T>150$ ). The lowest result was observed for IL with cation comprising an oleyl substituent (6). The results obtained for T. confusum beetles were presented in Fig. 2.

The beetles of $T$. confusum exhibited lower susceptibility to the tested ILs when compared to $S$. granarius. Again, the highest $T$ value was calculated for 3 . ILs with structurally small cations $(\mathbf{1}, 5)$ presented the lowest activity, their values of $T$ did not exceed 50. The results calculated for larvae of $T$. confusum were presented in Fig. 3.
Within the same species, larvae present significantly lower sensitivity to the tested ILs. The highest $T$ values were calculated for ILs with a long alkyl substituent in the cation - tetradecyltrimethylammonium (2) and didecyldimethylammonium (3). Small-sized cations acted as attractants, causing the larvae to preferably consume food covered with tested ILs in the nochoice test. The antifeedant activity of the synthesized bio-ILs towards larvae of $T$. granarium was presented in Fig. 4.

Similar observations were made in case of $T$. granarium larvae. Surprisingly, the lowest activity was established for the IL with hydrogenated tallow cation (4), which comprises two long saturated alkyl chains. Instead of preventing, the IL promoted the consumption of covered food in both choice and no-choice tests. On the other hand, ILs with a single tetradecyl (2) or two dodecyl (3) substituents with similar structures presented very good antifeedant properties. The difference in the obtained results may be caused by specific composition of substituents in the cation, which naturally occur in animal fat. This may make IL 4 a potentially attractive source of energy.

T. granarium is mainly known as a pest in crop storage areas which has adapted to the uptake of plant food. Nevertheless, the notable majority of the remaining Trogoderma species, 150 of which were described all over the world, ${ }^{36}$ feeds on animalbased food. In most cases this includes dried leathers and animal carcasses in the state of advanced decay, when the skeleton is covered only by skin, tendons and other poorly biodegradable body parts. The larvae of the Trogoderma species may also feed on feathers and hair. The attractiveness of the IL which contained a cation with a substituent based on animal fat

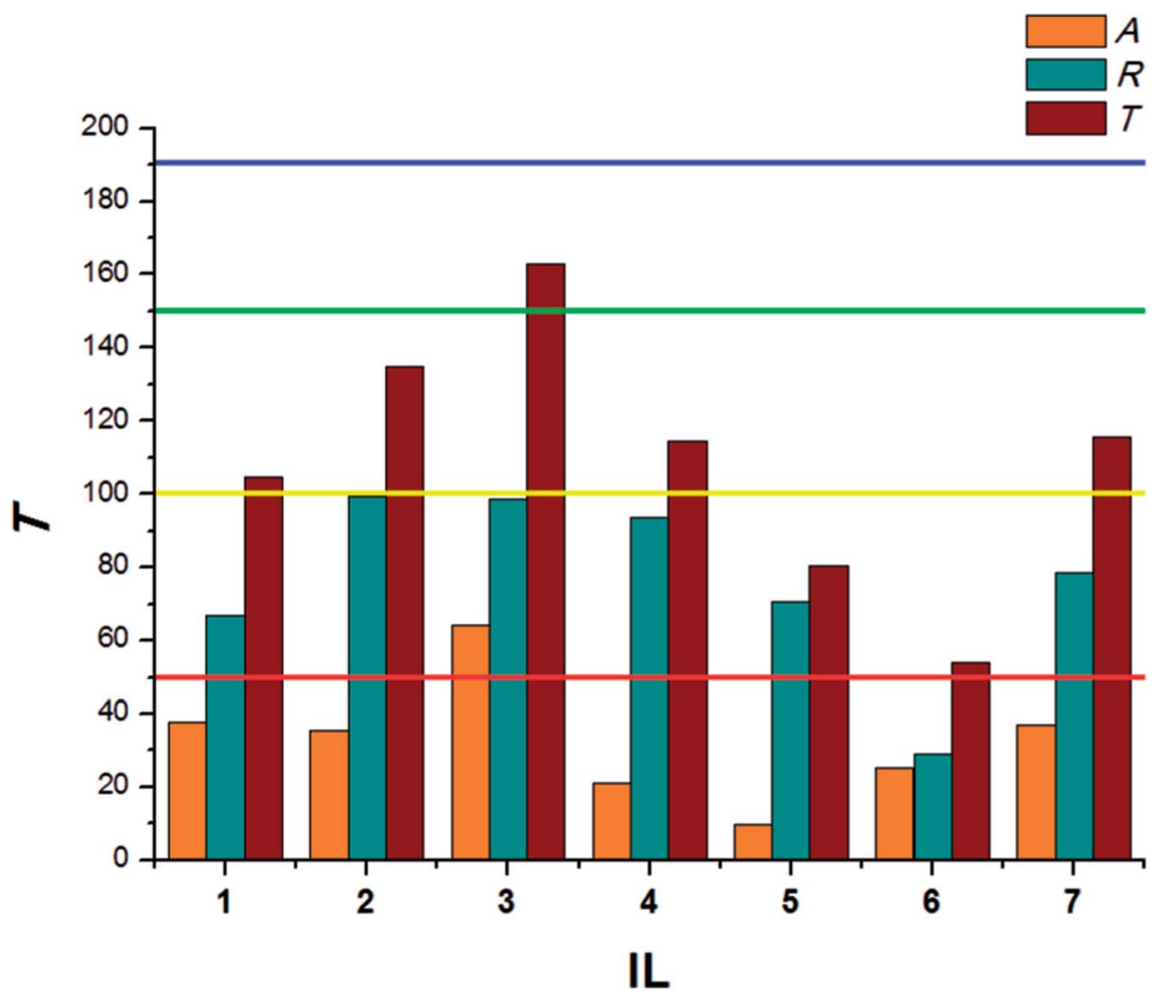

Fig. 1 Deterrent activity of bio-ILs (1-7) towards beetles of S. granarius. 


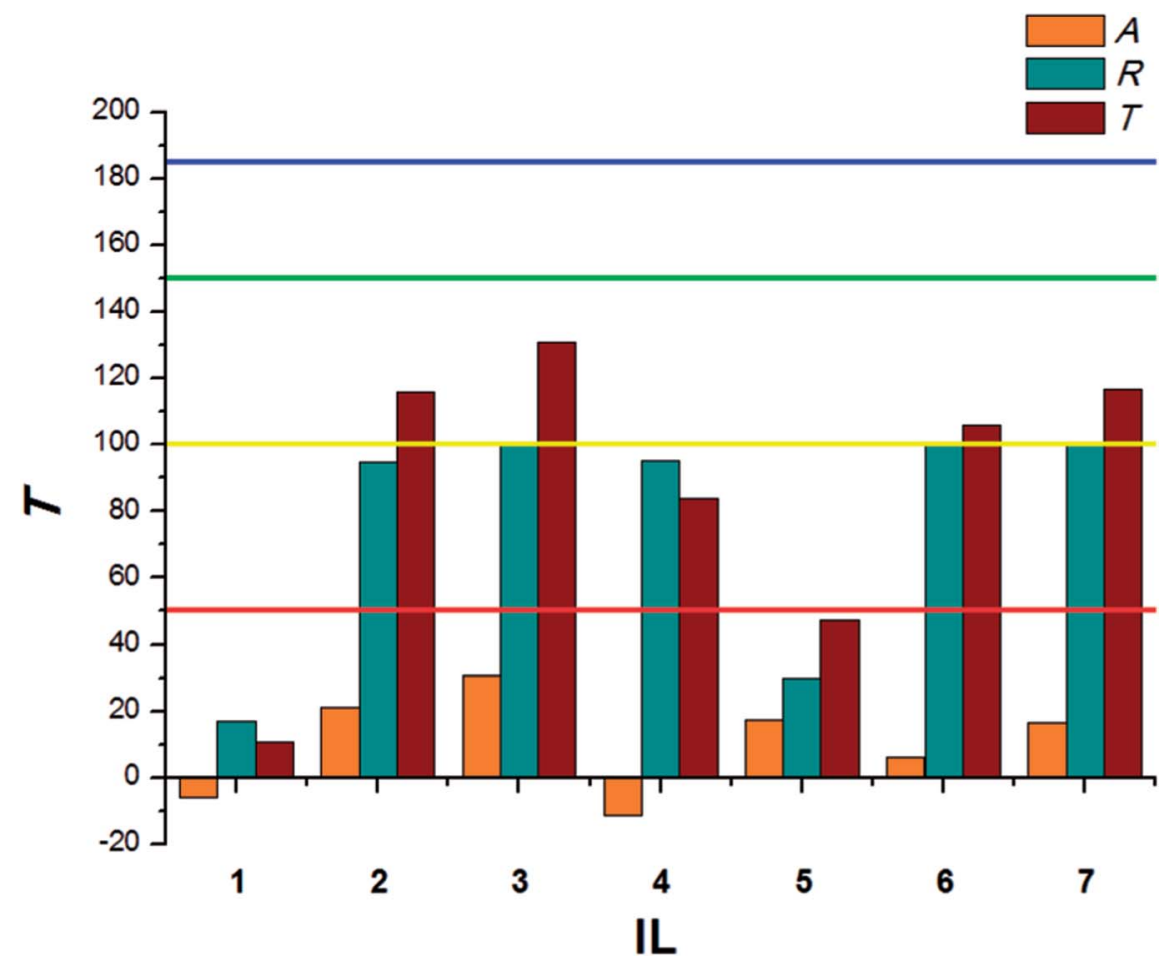

Fig. 2 Deterrent activity of bio-ILs (1-7) towards beetles of $T$. confusum.

to $T$. granarium may indicate the presence of primal substrate preferences of this species.

The presented results show the importance of ammonium bio-ILs as antifeedants with a wide spectrum of activity. The tested organisms presented large differences in susceptibility to the synthesized bio-ILs. The highest $T$ values were calculated for ILs with long saturated substituents $(2,3)$, making them the most universal among the obtained compounds. In our

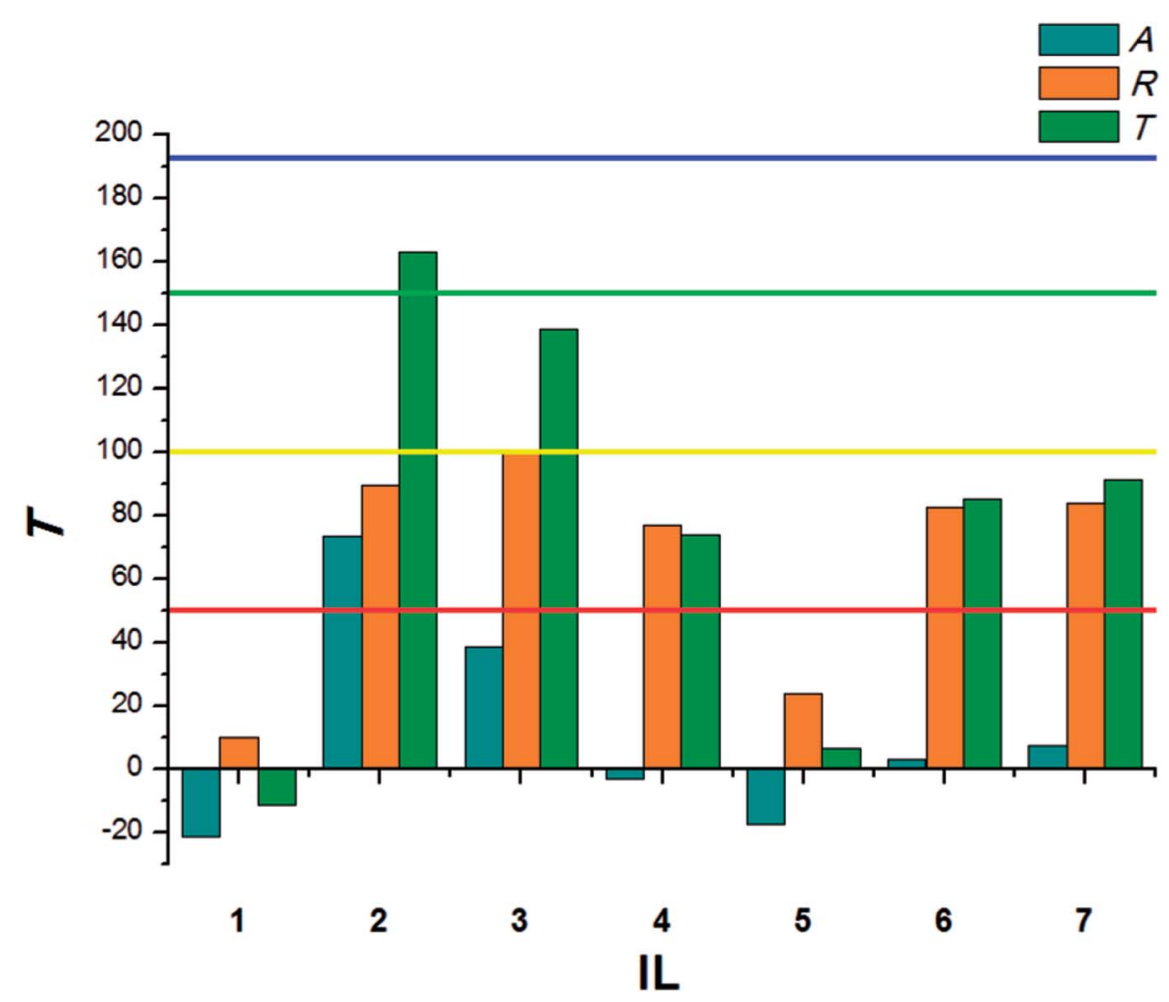

Fig. 3 Deterrent activity of bio-ILs (1-7) towards T. confusum larvae. 


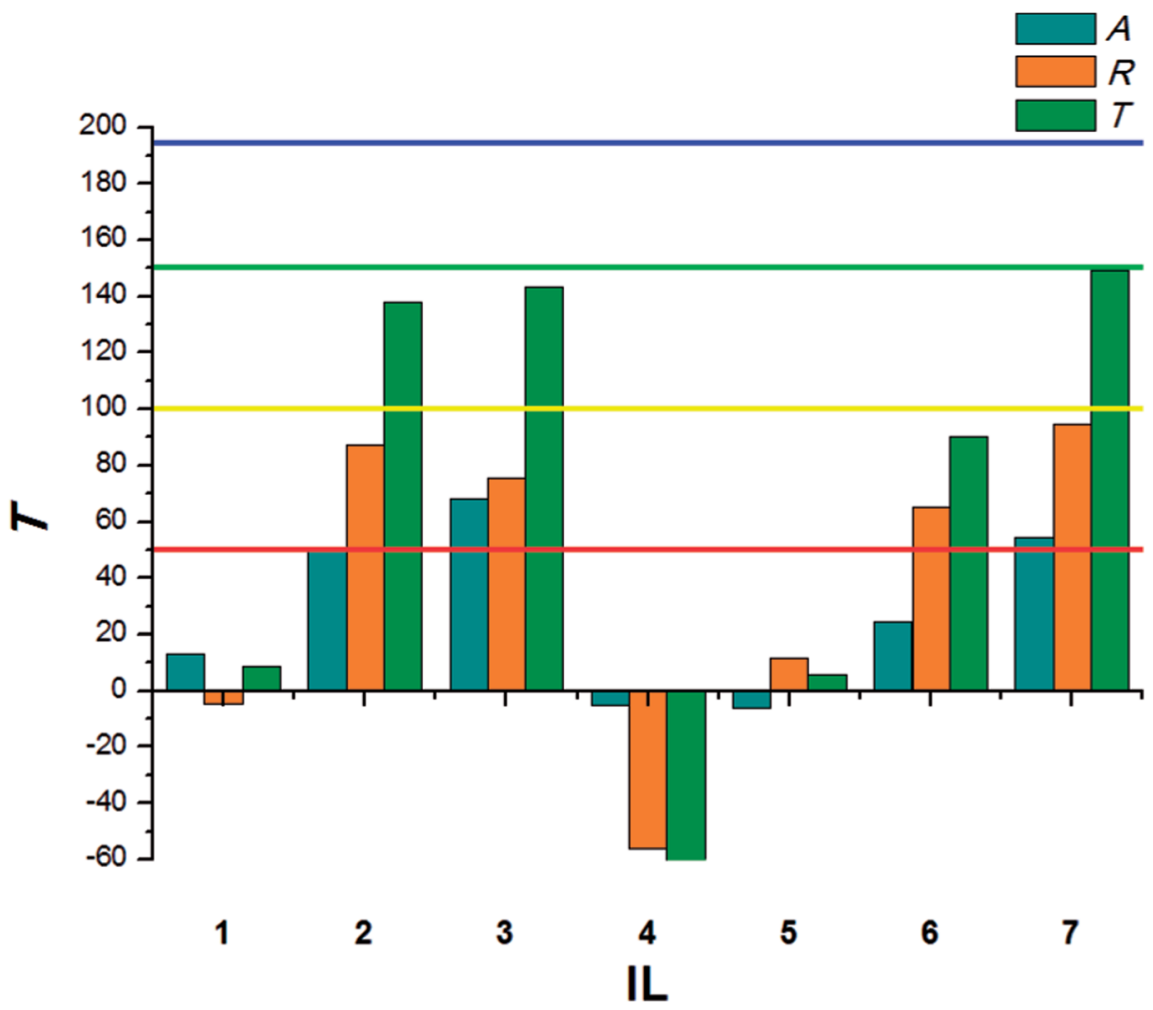

Fig. 4 Deterrent activity of bio-ILs (1-7) towards T. granarium.

previous studies, the best antifeedant parameters were also exhibited by didecyldimethylammonium ILs, however, as shown in the described results, the origin of anions used also plays a significant role in the final antifeedant effectiveness of the $\mathrm{IL}^{27}$ The lower sensitivity to the tested ILs presented by larvae may be caused by higher amounts of food consumed needed for development.

The first published report regarding bio-ILs as adjuvants for sulfonylurea herbicides prompted us to investigate the synthesized ILs based on the cheap and increasingly available camelina oil as potential adjuvants of popular herbicides. ${ }^{37}$
Herbicide treatments consisted of nicosulfuron (Henik 50 SG) and ILs with fatty acid anions isolated from camelina oil or fatty acid methyl esters (Actirob $842 \mathrm{EC}$ ) as reference adjuvant tested against common lambsquarters, cornflower and silky bent grass. The results were given as reduction in fresh weight of plants in Table 4.

Nicosulfuron applied alone at $30 \mathrm{~g} \mathrm{ha}^{-1}$ did not demonstrate herbicidal activity. The addition of adjuvants notably improved the herbicidal efficacy in all treatments. Results obtained for common lambsquaters and silky bent grass showed significant differences only in case of combinations with and

Table 4 Fresh weights reduction of plants treated with nicosulfuron at $30 \mathrm{~g}$ ai per ha with and without adjuvants at three weeks after application

\begin{tabular}{|c|c|c|c|c|c|}
\hline \multirow{2}{*}{$\begin{array}{l}\text { Tank-mix } \\
\text { partner } \\
\mathbf{1}\end{array}$} & \multicolumn{5}{|c|}{ Fresh weight reduction $^{a}[\%]$} \\
\hline & \multicolumn{2}{|c|}{ Common lambsquarters } & \multicolumn{2}{|c|}{ Cornflower } & Silky bent grass \\
\hline 2 & 84 & $\mathrm{~A}$ & 81 & $\mathrm{ab}$ & 93 \\
\hline 3 & 89 & $\mathrm{~A}$ & 85 & a & 91 \\
\hline 4 & 89 & A & 83 & $\mathrm{ab}$ & 93 \\
\hline 7 & 88 & A & 81 & $a b$ & 89 \\
\hline Actirob & 89 & A & 82 & $\mathrm{ab}$ & 91 \\
\hline None & 3 & $\mathrm{~B}$ & 8 & $\mathrm{c}$ & 0 \\
\hline HSD & 26.5 & & 12.1 & & 29.7 \\
\hline
\end{tabular}

${ }^{a}$ Values follow by the same letter in the same column are not significantly different $(P=0.05)$. 
without adjuvants. In these cases bio-ILs with fatty acid anions isolated from camelina oil showed similar efficacy as the commercial adjuvant and a level of reached weed control above $80 \%$. Slightly different situation was observed in case of cornflower. Among combinations with adjuvants, the lowest efficacy was demonstrated by IL $\mathbf{5}$, whereas the highest by IL $\mathbf{3}$. Bioassay results show that ILs 1-7 were as effective as the commercial adjuvant in terms of improving the herbicidal activity of nicosulfuron. It is worth mentioning that the high efficacy of ILs was obtained using doses lower by approx. half compared to the adjuvant available on the market (Actirob 842 EC). Research indicated that ILs based on vegetable oils can be used as effective adjuvants for herbicides belonging to the sulfonylurea group.

\section{Conclusions}

We confirmed that camelina oil is a good source of anions for the synthesis of bio-ILs. The reaction between camelina oil and quaternary ammonium hydroxides in propan-2-ol occurs rapidly with a high yield and glycerine is the by-product. The obtained ILs are thermally stable, high viscosity liquids, unaffected by the contact with air and organic solvents.

As presented in the framework of the study, it is possible to obtain bio-ILs, which are soluble in water as well as strongly hydrophobic solvents. ILs with fatty acid anions isolated from camelina oil and cations comprising two decyl or hydrogenated tallow substituents are soluble in hexane.

The synthesized ILs displayed deterrent activity with a strong influence of the cation type. Very good deterrent activity was noted for bio-ILs with the tetradecyltrimethylammonium and didecyldimethylammonium cations. The observed deterrent activity ranging from a lack of effect to excellent action results from the cation structure, nevertheless, the type of anion also contributes to such a strong diversity of activity. The presented results show the importance of ammonium bio-ILs as antifeedants with a wide spectrum of activity. At the same time, the studied bio-ILs are effective adjuvants for herbicides belonging to the sulfonylurea group. They exhibited high efficacy despite the fact that they were applied at a dose which was lower by approx. half compared to that used in commercial adjuvants. The excellent results obtained in the framework of this study open a new era of adjuvant ILs.

In summary, it is worth emphasizing that third generation bio-ILs were synthesized from a cheap and increasingly available camelina oil. Apart from the production of biodiesel, renewable diesel and renewable jet fuel, camelina oil is also a potential resource for the production of novel agrochemicals.

\section{Conflicts of interest}

There are no conflicts to declare.

\section{Acknowledgements}

This work was supported by 03/32/DSPB/0808, Poznan University of Technology, Department of Chemical Technology.

\section{References}

1 J. D. Holbrey and K. R. Seddon, Ionic Liquids, Clean Technol. Environ. Policy, 1999, 1, 223-236, DOI: 10.1007/s/ 100980050036.

2 W. L. Hough, M. Smiglak, H. Rodriguez, R. P. Swatloski, S. K. Spear, D. T. Daly, J. Pernak, J. E. Grisel, R. D. Carliss, D. M. Soutullo, J. H. Davis and R. D. Rogers, The third evolution of ionic liquids: active pharmaceutical ingredients, New J. Chem., 2007, 31, 1429-1436, DOI: 10.1039/b706677p.

3 K. Bica and R. D. Rogers, Confused ionic liquid ions - A "liquification" and dosage strategy for pharmaceutically active salts, Chem. Commun., 2010, 46(8), 1215-1217, DOI: 10.1039/b925147b.

4 J. L. Shamshina, P. S. Barber and R. D. Rogers, Ionic liquids in drug delivery, Expert Opin. Drug Delivery, 2013, 10, 13671381, DOI: 10.1517/17425247.2013.808185.

5 J. L. Shamshina, S. P. Kelley, G. Gurau and R. D. Rogers, Develop ionic liquid drugs, Nature, 2015, 528, 188-189, DOI: 10.1038/528188a.

6 J. Pernak, A. Syguda, D. Janiszewska, K. Materna and T. Praczyk, Ionic liquids with herbicidal anions, Tetrahedron, 2011, 67(26), 4838-4844, DOI: 10.1016/ j.tet.2011.05.016.

7 T. Praczyk, P. Kardasz, E. Jakubiak, A. Syguda, K. Materna and J. Pernak, Herbicidal ionic liquids with 2,4-D, Weed Sci., 2012, 60(2), 189-192, DOI: 10.1614/WS-D-11-00171.1.

8 J. Pernak, M. Niemczak, K. Materna, K. Żelechowski, K. Marcinkowska and T. Praczyk, Synthesis, properties and evaluation of biological activity of herbicidal ionic liquids with 4-(4-chloro-2-methylphenoxy)butanoate anion, $R S C$ Adv. , 2016, 6, 7330-7338, DOI: 10.1039/c5ra23997d.

9 M. Niemczak, R. Giszter, K. Czerniak, K. Marcinkowska and F. Walkiewicz, Bis(ammonium) ionic liquids with herbicidal anions, RSC Adv., 2015, 5, 15487-15493, DOI: 10.1039/ c4ra16151c.

10 M. Niemczak, A. Biedziak, K. Czerniak and K. Marcinkowska, Preparation and characterization of new ionic liquid forms od 2,4-DP herbicide, Tetrahedron, 2017, 73, 7315-7325, DOI: 10.1016/j.tet.2017.11.032.

11 O. A. Cojocaru, J. L. Shamshina, G. Gurau, A. Syguda, T. Praczyk, J. Pernak and R. D. Rogers, Ionic liquid forms of the herbicide dicamba with increased efficacy and reduced volatility, Green Chem., 2013, 15(8), 2110-2120, DOI: $10.1039 / \mathrm{c} 3 g \mathrm{c} 37143 \mathrm{c}$.

12 J. Pernak, R. Giszter, A. Biedziak, M. Niemczak, R. Olszewski, K. Marcinkowska and T. Praczyk, Alkyl $\left(\mathrm{C}_{16}, \mathrm{C}_{18}, \mathrm{C}_{22}\right)$ trimethylammonium-Based Herbicidal Ionic Liquids, $J$. Agric. Food Chem., 2017, 65, 260-269, DOI: 10.1021/ acs.jafc.6b04528.

13 J. Zhu, G. Ding, Y. Liu, B. Wang, W. Zhang, M. Guo, Q. Geng and Y. Cao, Ionic liquid forms of clopyralid with increased efficacy against weeds and reduced leaching from soils, Chem. Eng. J., 2015, 279, 472-477, DOI: 10.1016/ j.cej.2015.05.025. 
14 G. Ding, Y. Liu, B. Wang, D. Punyapitak, M. Guo, Y. Duan, J. Li and Y. Cao, Preparation and characterization of fomesafen ionic liquids for reducing the risk to the aquatic environment, New J. Chem., 2014, 38, 5590-5596, DOI: 10.1039/c4nj01186d.

15 B. Wang, G. Ding, J. Zhu, W. Zhang, M. Guo, Q. Geng, D. Gou and Y. Cao, Development of novel ionic liquids based on bentazone, Tetrahedron, 2015, 71, 7860-7864, DOI: 10.1016/j.tet.2015.08.029.

16 J. Pernak, M. Niemczak, R. Giszter, J. L. Shamshina, G. Gurau, O. A. Cojocaru, T. Praczyk, K. Marcinkowska and R. D. Rogers, Glyphosate-Based Herbicidal Ionic Liquids with Increased Efficacy, ACS Sustainable Chem. Eng., 2014, 2, 2845-2851, DOI: 10.1021/sc500612y.

17 H. Choudhary, J. Pernak, J. Shamshina, M. Niemczak, R. Giszter, Ł. Chrzanowski, T. Praczyk, K. Marcinkowska, O. A. Cojocaru and R. D. Rogers, Two Herbicides in a Single Compound: Double Salt Herbicidal Ionic Liquids Exemplified with Glyphosate, Dicamba, and MCPA, ACS Sustainable Chem. Eng., 2017, 5, 6261-6273, DOI: 10.1021/ acssuschemeng.7b01224.

18 J. Pernak, M. Niemczak, J. L. Shamshina, G. Gurau, G. Głowacki, T. Praczyk, K. Marcinkowska and R. D. Rogers, Metsulfuron-methyl-based herbicidal ionic liquids, J. Agric. Food Chem., 2015, 13, 3357-3366, DOI: 10.1021/jf505782p.

19 J. Pernak, K. Czerniak, M. Niemczak, Ł. Ławniczak, D. K. Kaczmarek, A. Borkowski and T. Praczyk, Bioherbicidal ionic liquids, ACS Sustainable Chem. Eng., 2018, 6, 2741-2750, DOI: 10.1021/acssuschemeng.7b04382.

20 G. Tang, B. Wang, G. Ding, W. Zhang, Y. Liang, C. Fan, H. Dong, J. Yang, D. Kong and Y. Cao, Developing ionic liquid forms of picloram with reduced negative effects on the aquatic environment, Sci. Total Environ., 2018, 616617, 128-129, DOI: 10.1016/j.scitotenv.2017.10.288.

21 J. Pernak, M. Niemczak, K. Zakrocka and T. Praczyk, Herbicidal ionic liquid with dual-function, Tetrahedron, 2013, 69, 8132-8136, DOI: 10.1016/j.tet.2013.07.053.

22 J. Pernak, B. Markiewicz, B. Łęgosz, F. Walkiewicz, R. Gwiazdowski and T. Praczyk, Known triazole fungicides - a new trick, RSC Adv., 2015, 5, 9695-9702, DOI: 10.1039/ c4ra12160k.

23 K. Bica, L. R. Cooke, P. Nugent, C. Rijiksen and R. D. Rogers, Toxic on purpose: ionic liquid fungicides as combinatorial crop protecting agents, Green Chem., 2011, 13, 2344-2346, DOI: $10.1039 / \mathrm{c} 1 \mathrm{gc} 15170 \mathrm{c}$.

24 B. Markiewicz, A. Sznajdrowska, Ł. Chrzanowski, Ł. Ławniczak, A. Zgoła-Grześkowiak, K. Kubiak, J. Nawrot and J. Pernak, Ionic liquids with a theophyllinate anion, New J. Chem., 2014, 38, 3146-3153, DOI: 10.1039/c4nj00463a.

25 M. Śmiglak, R. Kukawka, P. Lewandowski, M. Budziszewska, A. Obrępalska-Stęplowska, K. Krawczyk, A. Zwolińska and H. Pospieszny, New Dual Functional Salts Based on
Cationic Derivative of Plant Resistance Inducer-Benzo [1.2.3]thiadiazole-7-carbothioic Acid, S-Methyl Ester, ACS Sustainable Chem. Eng., 2016, 4, 3344-3351, DOI: 10.1021/ acssuschemeng.6b00398.

26 M. Śmiglak, P. Lewandowski, R. Kukawka, M. Budziszewska, K. Krawczyk, A. Obrępalska-Stępłowska and H. Pospieszny, Dual Functional Salts of Benzo[1.2.3]thiadiazole-7carboxylates as a Highly Efficient Weapon Against Viral Plant Diseases, ACS Sustainable Chem. Eng., 2017, 5, 41974204, DOI: 10.1021/acssuschemeng.7b00161.

27 J. Pernak, B. Łęgosz, F. Walkiewicz, T. Klejdysz, A. Borkowski and . Chrzanowski, Ammonium ionic liquids with anions of natural origin, $R S C A d v ., 2015,5,65471-65480$, DOI: $10.1039 / \mathrm{c} 5 \mathrm{ra} 11710 \mathrm{k}$.

28 T. Klejdysz, B. Łęgosz, D. Czuryszkiewicz, K. Czerniak and J. Pernak, Bio-based ionic liquids with abietate anion, ACS Sustainable Chem. Eng., 2016, 4, 6543-6550, DOI: 10.1021/ acssuschemeng.6b01381.

29 J. Pernak, K. Czerniak, A. Biedziak, K. Marcinkowska, T. Praczyk, K. Erfurt and A. Chrobok, Herbicidal ionic liquids derived from renewable sources, $R S C A d v ., 2016,6$, 52781-52789, DOI: 10.1039/c6ra06703d.

30 D. J. Wysocki, T. G. Chastain, W. F. Schillinger, S. O. Guy and R. S. Karow, Camelina: seed yield response to applied nitrogen and sulfur, Field Crops Res., 2013, 145, 60-66, DOI: 10.1016/j.fcr.2013.02.009.

31 A. Popa, S. Jurcoane and B. Dumitriu, Camelina sativa oil - A Review, Scientific Bulletin Series F. Biotechnologies, 2017, 21, 233-238, ISSN 2285-1364, CD-ROM ISSN 2285-5521, ISSN Online 2285-1372, ISSN-L 2285-1364.

32 M. Berti, R. Gesch, C. Eynck, J. Anderson and S. Cermak, Camelina uses, genetics, genomics, production, and management, Ind. Crops Prod., 2016, 94, 690-710, DOI: 10.1016/j.indcrop.2016.09.034.

33 A. A. C. Toledo Hijo, G. J. Maximo, R. L. Cunha, F. H. S. Fonseca, L. P. Cardoso, J. F. B. Pereira, M. C. Costa, E. A. C. Batista and A. J. A. Meirelles, Phase equilibrium and physical properties of biobased ionic liquid mixtures, Phys. Chem. Chem. Phys., 2018, 20, 64696479, DOI: 10.1039/c7cp06841g.

34 B. S. Furniss, A. J. Hannaford, P. W. G. Smith and A. R. Tatchell, Vogel's Textbook of Practical Organic Chemistry, Longman, Harlow, 5 edn, 1989.

35 M. Szczepanik, R. Obara, A. Szumny, B. Gabryś, A. Halarewicz-Pacan, J. Nawrot and C. Wawrzeńczyk, Synthesis and insect antifeedant activity of precocene derivatives with lactone moiety, J. Agric. Food Chem., 2005, 53, 5905-5910, DOI: 10.1021/jf058034j.

36 J. Háva, World Catalogue of Insects. Vol. 13. Dermestidae (Coleoptera), Brill, Leiden, Boston, 2015.

37 K. Marcinkowska, T. Praczyk, B. Łęgosz, A. Biedziak and J. Pernak, Bio-ionic liquids as adjuvants for sulfonylurea herbicides, Weed Sci., 2018, 66, 404-414. 